\title{
Subacute Sclerosing Pan-Encephalitis (SSPE) - Past and Present
}

\author{
Natan Gadoth \\ Department of Neurology, Maynei Hyeshuah Medical Center, \\ Bnei Barak, and The Sackler Faculty of Medicine, \\ Tel-Aviv University \\ Israel
}

\section{Introduction}

Subacute Scerosing Pan Encephalitis (SSPE), a devastating brain disease of young children was frequently taken into account in the differential diagnosis of the so-called "neurodegenerative diseases of childhood" by paediatricians, child neurologist and psychiatrists during the second half of the last century. Fortunately, this diagnosis is considered very rarely today in well developed countries, mainly in the western hemisphere. This does not mean that the disease "vanished" although its incidence dramatically declined.

One of the reasons to include SSPE in a book dedicated to "encephalitis " is not only for historical purposes, but also to remind the young generation of physicians dealing with neuro-psychiatric disorders of children and young adults, that SSPE still exists.

Another goal of this chapter is to point out the reasons why SSPE is one of several disorders which fulfil the concept of "slow virus infection", a term brought up by Bjorn Sigurdsson in 1954, after he and his co-workers discovered that three sheep diseases, scrapie, visna, and sheep pulmonary adenomathosis are all caused by the same retrovirus. This revolutionary concept was later utilized by D. Carleton Gajdusek to study "infections of unknown origin" such as Kuru and Creuzfeldt-Jacob disease. The new generation of paediatricians and child neurologists who most probably have never seen a case of SSPE, will quite naturally skip the paragraph in the text-book which is dedicated to this disease. For those young colleagues this chapter may be more than "interesting" or "informative". It is written for them and hopefully may help them to diagnose correctly their first case and offer the present available palliative drug treatment. Regarding the readers in the field of public health, it may enhance their drive to achieve widespread and complete coverage of measles immunization of populations at risk.

\section{History}

The suggestion that SSPE may be a viral infection was raised by Dawson who published 2 consecutive papers in 1933 and 1934 in which he described 2 children from Tennessee who died after a progressive course characterized by involuntary jerking of the limbs and mental deterioration. In their brains he noted encephalitic changes with intracellular eosinophilic inclusion bodies in numerous cortical neurons which reminded him of viral inclusions. 
(Dawson, 1933; 1934). In 1939, an additional case was described in Germany. This was a 17 year old boy who died after 2 years of progressive neurological deterioration.In his brain nodular changes in the white and gray matter resembling "encephalomyelitis with characteristics of Japanese Encephalitis", were observed. (Pette \& Döring, 1939, Case 3). In 1945, Van Bogaert described a clinically similar case in whom the dominant neuropathological features consisted of demyelination and glial proliferation in the white matter which were summarized by him as "subacute sclerosing leukoencephalitis" (Van Bogaert, 1945). Thus, at this stage, 4 children with similar clinical features of progressive fatal neuro- behavioural deterioration and "jerks", have been described. However, in their brains variable and non uniform pathological findings including inflammatory changes, intraneuronal inclusion bodies, nodular "sclerotic" changes both in the white and gray matter were reported and demyelination with glial proliferation in the white matter.

During the next few years children with diverse clinical features resembling progressive encephalitis have been described. However, only in 1957, Poser and Radermecker reached the conclusion that all those patients suffer from a similar disorder which they called Subacute Sclerosing Leucoencephalitis. (Poser \& Radermecker, 1957). They based their conclusion on a study of 7 cases including 3 post- mortem examinations. Finally, the term SSPE was coined by Greenfield in 1950 (Greenfield, 1950). Boutellie should be credited for his significant contribution to the understanding of the true nature of SSPE. With the aid of the electron- microscope he identified structures which resembled nucleocapsids of paramyxovirus in SSPE (Boutellie et al., 1965). This finding was soon followed by a search for antibodies to paramyxovirus in the blood and CSF of patients with SSPE which yielded very high titers of anti- measles antibodies in the blood and CSF of all patients studied (Connolly et al., 1967). These pivotal findings led to the crucial conclusion that SSPE is related to infection with measles virus (MV). Later, the mechanisms by which this virus is able to persists in nerve cells for long periods of time in a dormant form were elucidated and shed light on the processes involved in "slow virus infection". The conclusion reached by epidemiological observations that there is a relation between early measles infection and SSPE led to a world-wide measles immunization program followed by a dramatic decline in the incidence of SSPE, up to the present situation where in most of the western developed countries, SSPE was almost completely eradicated.

\section{The clinical spectrum of SSPE}

There are 2 forms of encephalitis following measles infection. The first is the relatively common acute post infections measles encephalitis which develops in about 0.1 percent of immunocompetent patients and carries a 20 percent mortality rate. This form of encephalitis is not caused by direct invasion of the brain by MV. Indeed, only with highly sensitive methods could MV specific nucleic acids be detected in the brains of patients with this form of encephalitis. Those findings are in line with the assumption that this is a true example of measles virus induced pathological immune mediated "post-infectious" encephalitis. In contras, MV is present in the brains of the immunocompetent patients and causes SSPE while in immunocompromized patients it causes Measles Inclusion Body Encephalitis. Both conditions are fatal and present clinically months or years after the initial measles infection. The clinical presentation of SSPE is often insidious and frequently attributed to psychological or behavioural problems. The exception to this are those cases who present acutely with focal neurological signs and progress rapidly to coma and death. 
The following case report is a classical example of the fulminant form of SSPE which affects about $10 \%$ of all patients (PeBenito et al., 1997).

\subsection{Case report 1}

This 7 year old, previously healthy boy was born in 1970 to healthy unrelated parents of Jewish -Yemenite origin. He was brought to the emergency room (ER), at the Beilinson Medical Center in the state of semi- coma.Past medical and family history were noncontributory. He was well until 2 days prior to admission when mild fever was followed by complains of right sided difficulties in using his hand and leg. He was previously seen by a local physician who diagnosed " common cold ". In the ER his Glasgow Coma Scale Score was $6 / 15$ (eye opening 1 , best verbal response 1 , best motor response 4 ). The abnormal neurological findings were lack of withdrawal from deep pain with brisk DTR's and extensor plantar response on the right side. There were no involuntary movements. Immediate brain CT followed by 4 vessel cerebral angiography were normal. An EEG disclosed rhythmic periodic delta generalized discharges with flat electrical background. A lumbar puncture disclosed normal opening pressure, crystal clear sterile CSF with slightly increased protein, normal glucose and negative Gram stain. Serum measles antibody titer by complement fixation was 1:256 and that of the CSF 1:16. There were no clinical signs of measles. The boy died on the $3^{\text {rd }}$ hospital day and the autopsy confirmed the clinical diagnosis of SSPE. He had measles at the age of 2 years and did not receive measles vaccination.

\section{The following case report represents the protracted and peculiar clinical course of SSPE}

\subsection{Case report 2}

This 16 year old girl was born in 1963 to healthy Jewish parents who immigrated to Israel from Morocco in 1949. Her past medical and developmental history was unremarkable. There was no history of clinical measles or an exanthematous early febrile illness. She received measles immunization soon after it was initiated in Israel during 1967. At the age of 7 years, during the second elementary school year, an unexplained decline in her school performance was noted. A paediatric neurological assessment was summarized as Attention Deficit Disorder for which supplementary teaching and Methylphenidate (Ritalin $\left.{ }^{R}\right) 10 \mathrm{mg}$ daily was prescribed. An EEG showed right sides periodic delta wave discharges and for that brain CT with contract enhancement was done and read normal. The EEG findings were attributed to "sweating artefact".The clinical course was stable for 18 months during which a slow deterioration was noticed in her general alertness and vigilance according to the mother. This was however denied by her school teachers who thought that she did quite well in school and received excellent school reports. The anxious mother consulted several child neurologists and psychiatrists who failed to find any abnormalities. A repeated EEG showed generalized periodic slow delta bursts with slow background activity. Serum and CSF measles antibody titers by complement fixation were 1: 256 and 1:32 respectively. A diagnosis of SSPE was considered for which daily Isoprinosine and several courses of intravenous "Thymic Humoral Factor" (THF), were given as part of 2 experimental treatment trials which were at that time done in Israel. That was followed by clinical improvement in her vigilance. She enjoyed the routine daily life of a young girl until the age of 11 years when frequent falls, schoolwork deterioration and sudden brief neck and back flexion movements associated with the falls were noted. She started to behave "strangely", 
and had difficulties in recognition of familiar faces and objects. When examined by me for the first time she had marked visual agnosia and neck and axial myoclonus. Her EEG showed additional background slowing with "metronomic" delta bursts resembling "Burst Suppression" pattern. Clonazepam (clonex ${ }^{\mathrm{R}}$ ) was helpful only for a short period of time. Both serum and CSF measles antibody titers, and brain CT were almost unchanged.

Her condition gradually deteriorated. She spent her last 2 years of life in a nursing home during which continuous very high fever unresponsive to a variety of antipyretics, bouts of sweating accompanied by brady-tachy arrhythmia, and generalized rigidity were present. Her EEG was almost isoelectirc without evidence of periodic bursts during the last weeks of her life. She died of aspiration pneumonia. Autopsy was not permitted for religious reasons. Those 2 cases represent the wide spectrum of the clinical features and course of SSPE and also the difficulties of considering SSPE in the differential diagnosis at the early stags of the disease, a fact which explains the delay in the diagnosis in some cases.

The classical clinical diagnostic features of SSPE are shown in Table 1, and the clinical staging of the disease is shown in table 2.

Childhood onset of mental and behavioral regression with :

- Myoclonic Jerks

- $\quad$ EEG- Generalized bilateral rhythmic synchronous bursts of spike-wave or slow wave complexes

- Elevated measles antibody titers in serum and CSF without concomitant evidence of clinical measles

- $\quad$ Elevated CSF IgG, presence of oligoclonal IgG bands

In the brain, presence of perivascular inflammatory cuffing, cortical and subcortical white matter astro-microgliosis, neurophagia and Cowdry type A, eosinophilic intaranuclear inclusion bodies

Table 1. SSPE - Clinical and laboratory diagnostic criteria

i. Personality changes accompanied by school failure and bizarre behavior

ii. Axial (Especially characteristic rapid neck flexion) massive myoclonus causing frequent and violent falls

iii. Generalized rigidity with extarapyramidal features and progressive unresponsiveness

iv. Minimal conscious state progressing to akinetic mutism with severe progressive autonomic failure

Table 2. Clinical staging of SSPE

\section{Characteristic clinical features}

The majority of the patients the initial symptoms are noted between the ages of 8-11 years, about 6-7 years after measles infection. Zilber et al. initiated a country survey of SSPE in Israel by obtaining information from the Israeli National Neurological Diseases Register (INNDR), the Central Virus Laboratory which at that time tested sera and CSF for measles 
antibodies throughout the country and the medical records of patients diagnosed with SSPE from all hospitals in the country between the years 1960-1973 (Zilebr at al., 1983). Hundred and eight such patients were detected, 40 of them were followed by the author of this chapter. The onset of SSPE accrued during 1968-1979. The mean age of onset was almost identical to that reported for children in USA (9.5 y.) and UK (9.8 y.). The interval (in years) between clinical measles and onset of SSPE in the Israeli children (7.4 y.), was also similar to that of USA and UK children (7.0 and 6.8 y. respectively). However, the interval (in years) between the time of measles vaccination and SSPE varied between 6.5 years in Israel, and 3.3 and 3.0 in the USA and UK respectively.

All Israeli children with SSPE had progressive neurobehavioral deterioration, myoclonic jerks and characteristic EEG. Sixty eight percent had elevated serum measles antibodies and $89 \%$ had increased titer of those antibodies in the CSF. A quite surprising finding was the low percentage of patients $(13 \%)$ with brain pathology characteristic of SSPE.

True epileptic seizures were a rarity. We have seen only 6 out of our cohort of 40 patients who had true epileptic seizures. Those were 5 boys and 1 girl who had a similar age of onset and disease features. The mean interval between SSPE onset and the first seizure was 15 months $(3$ - 24). The EEG was mostly focal and the response to Anti Convulsive Drugs (ACD) varied from excellent in 2 patients, good in one and poor in 2. One patient who failed to respond to ACD was given a ketogenic diet which was beneficial. The common denominator of these patients was antecedent neurological impairment. Four suffered from viral encephalitis at one year of age, one had severe learning problems diagnosed prior to the onset of SSPE and the sixth had severe congenital sensory-neural deafness. Two similar cases have been recently reported (Demir et al., 2009). In few patients focal seizures in the form of epilepsia partialis continua and an EEG showing Periodic Lateralizing Epileptic Discharges (PLED) were reported. This pattern was associated with a fulminant course (Santoshkumar \& Radhakrishnan 1996, Cherian et al., 2009). As mentioned above, earlier publications indicated that epileptic seizures are rare and appear at late stages of the disease. More recent publications such as the paper by Kissani (Kissani et al., 2001), indicate that epilepsy is rather frequent. In a series of 70 patients with SSPE from Morocco, 30 had

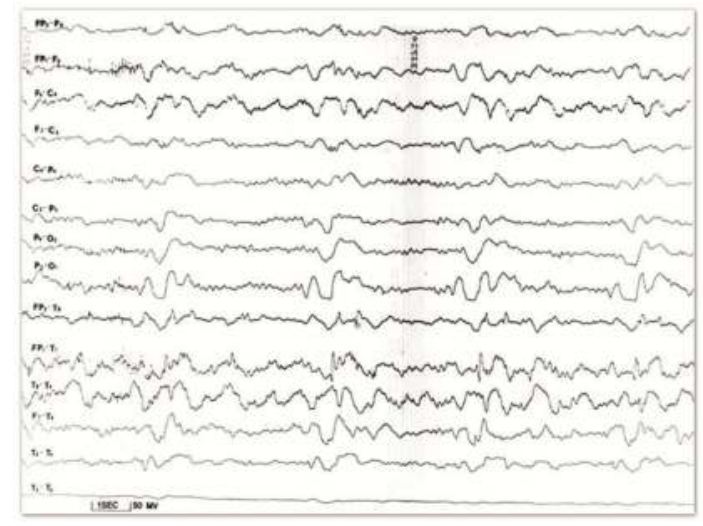

Fig. 1. Patients with SSPE and partial seizures. Note the slow background activity, continuous fronto-central delta activity, periodic non-rhytmic delta bursts and left anterior temporal spikes. 
true epileptic seizures.In two-thirds of them the seizures started during the first year of the disease and in $23 \%$, were the presenting symptom. Partial seizures with secondary generalization were most common in the very early stages of the disease and frequently led to the correct diagnosis. When seizures appeared late in the course of the disease (43\%), they were mainly generalized tonic-clonic (GTCS). The "heralding" partial seizures are most probably indicators of focal onset of encephalitis with generalized spread later on.

The diagnosis of SSPE is quite straight forward and easily reached in children if the attending paediatricians and child neurologists are familiar with the disease. This is quite different when the disease affects adults. The occurrence of SSPE in subjects older than 18 years is quite rare, comprising $1-12.7 \%$ of all patients (Prashanth et al., 2006). Adult onset SSPE presents at an average age of 25 years and rarely follows the classical clinical stages mentioned above. Visual symptoms at presentation are frequent (Singer et al., 1997), while myoclonus may be absent. About $30 \%$ of 52 such patients lacked a history of measles (Fabian et al., 2010).

\section{Electroencephalographic and neuroimaging features}

The most characteristic EEG feature is the periodic, stereotyped, high voltage discharges which appear concomitantly with the appearance of the myoclonic jerks. At early stages of the disease, the EEG may be normal or show moderate non-specific generalized slowing. As the diseases progresses, the periodic discharge pattern emerges, at first only during sleep, before myoclonic jerks are evident. In early stages, administration of IV diazepam can bring out the typical bursts. Somewhat later in the course and concomitantly with the appearance of typical myoclonus, the characteristic periodic discharge pattern can be seen also during wakefulness. This pattern consists of bilateral synchronous symmetrical bursts with an amplitude of 200-500 mV. Each burst consists of polyphasic, monomorphic delta waves. The bursts appear every 4-10 seconds with an identical morphology in any recording lead and are rhythmic ("metronomic"). The bursts are "time locked" with the myoclonic jerks. The interval between the bursts becomes shorter with disease progression. In advanced stages this pattern is replaced by disorganized slow delta rhythm. The voltage of the recording gets smaller and at stage IV it may became almost iso- electric (Figure.2)

In a relatively recent study from India (Praveen-Kumar et al., 2007), the EEG features of 58 patients with SSPE (stage I: $10.2 \%$; II: $64 \%$; III: $25.8 \%$ ), were analyzed and related to the stage of disease and neuroimaging findings. Bursts as defined above were found in $98 \%$ of the patients. Those were periodic in 55\%, "quasi-periodic" in 36\% and non-periodic in $6 \%$. The periodic bursts were asymmetrical in $33 \%$. The burst morphology, frequency and inter-burst interval were not influenced by hyperventilation, photic or sensory stimulation. Normal background was recorded in all patients in stage I, and slow background in all other stages. Spike and sharp wave epileptiform discharges were present in $72.4 \%$ of the patients. Those were mostly generalized and only in 10 patients epileptiform activity was lateralized or multifocal. The focal discharges were mostly fronto-parietal. Periodic Lateralizing Epileptic Discharges (PLED's), were present in 10 recordings. Asymmetry of background activity or bursts were associated with lateralizing neurological deficits. However, there was no correlation between the EEG asymmetry and CT or MRI findings. Brain neuroimaging was performed in 44 patients and both CT and MRI in 11 patients only. The main neuro-imaging findings consisted of brain oedema and atrophy seen in all stages of the disease while signal intensity changes were present in stages II-III. Parieto-occipital white matter was affected in 


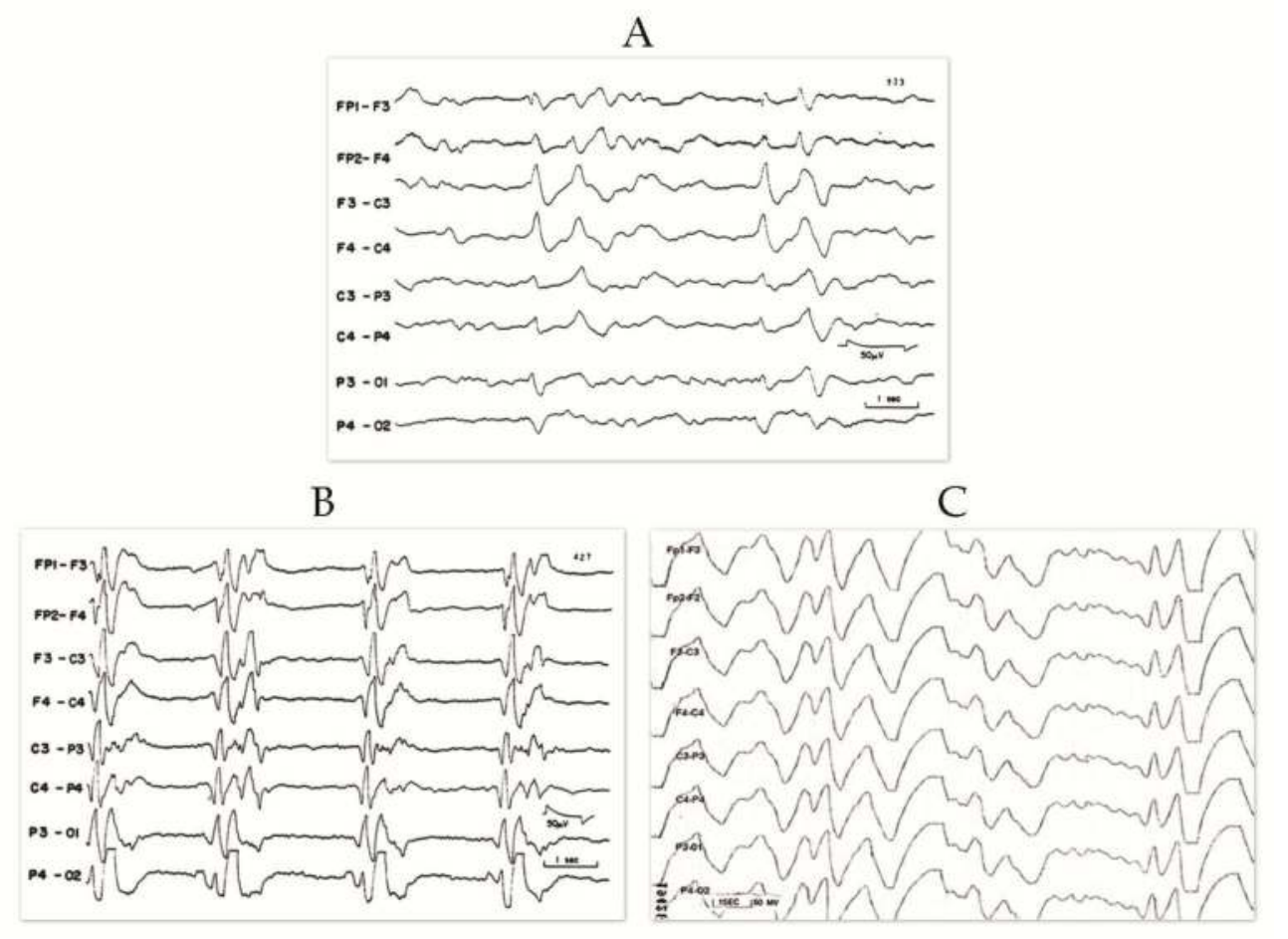

Fig. 2. EEG in various stages of SSPE. A: The background activity is disorganized with few repetitive high voltage delta bursts with fronto-central amplitude accentuation in the early stages of the disease. B: Typical "metronomic" delta burst pattern with almost flat amplitude during burst intervals recorded during the advanced stages of SSPE C: A uniform pattern of monomorphic slow waves at a very advanced stage of SSPE.

stage II while diffuse fronto-parteital changes were more common in stage II-III. There was no contrast enhancement by Iodine or Gadolinium. Although there was no correlation between the imaging features and focal EEG changes or the abnormal neurological findings, a significant association between visual deficits and parieto-occipital signal changes on MRI was found. In a more recent study (Aydin et al., 2009), 17 patients with SSPE who had a routine normal MRI and 30 healthy matched controls underwent T1-weighted magnetization-prepared rapid acquisition gradient echo images. When optimized method of voxel-based morphometry performed across-sectional analysis were applied to search for gray matter volume differences between the patients and controls, a fronto-temporal reduction of the cortical gray matter was found in the patients,regardless of the duration of symptoms or the presence and nature of neurological deficits.

\section{Neuropathology}

In the early phase of the disease brain oedema with DNA and RNA oxidative damage within infected cells are the typical findings. There is evidence of lipid peroxidation in areas of early demyelination (Hayashi et al., 2002). The main histopathological findings in the 
acute phase are inflammatory and consist of the classical cortical and subcortical "perivascular cuffing", spongiosis and demyelination, sparing the cerebellum (Figure 3).

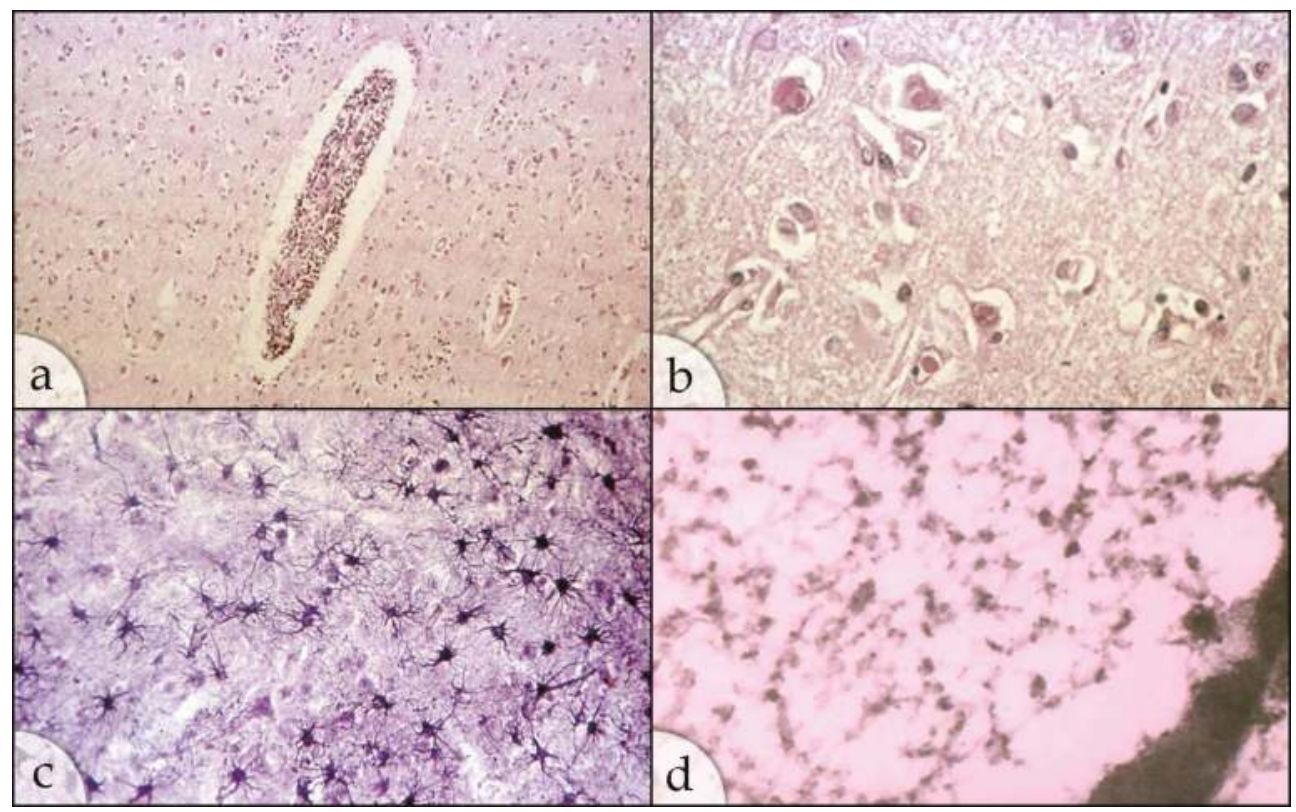

Fig. 3. Postmortem brain microscopy of SSPE. (a). Typical lymphocytic perivascular cuffing within brain parenchyma (H\&E, X100 ) (b). Cortical neurons with the characteristic intranuclear eosinophilic Cowdry type-A inclusions surrounded by a clear hallo (H\&E X400). (c). Profound astrocytic proliferation (PAS X190). (d). Elecromicrograph of an inclusion body showing curvilinear structures which are most probably viral nucleocapsids (X 20000).

Initially, posterior brain regions are the most affected. Pronounced changes are seen in the medial thalamus and the deep structures. With disease progression more anterior areas, brain stem and spinal cord are also affected. The inflammatory cellular response consists of focal and/or diffuse perivascular infiltrates of lymphocytes, plasma cells and phagocytes which are present within brain parenchyma as well as in the menings. The astrocytes, oligodendrocytes and microvascular endothelium are the mostly infected cell types (Allen et al., 1996).The nuclear and cytoplasmic inclusion bodies seen in neurons and oligodendrocytes are Cowdry type-A inclusions which contain homogeneous eosinophilic material. They are diffusely distributed mostly in the fulminant cases while the small multiple Cowdry type-B inclusion bodies, are almost always present in the brainstem. The nuclear inclusions correspond to measles viral particles and contain viral antigens. Neurofibrillary tangles may be present within neurons and oligodendrocytes. The tangles contain viral genome as shown by in-situ hybridization. Those findings suggest that the tangles are the result of the viral infection. (McQuaid et al., 1994). The inflammatory reaction and even the inclusion bodies are typical for the early stages of the disease and are hard to find at the later stages. Typically for SSPE as a model for slow virus infection, it is very 
difficult to isolate even a small amount of infectious virus from the brain while viral antigens can be quite easily identified.

\section{Immunopathology}

A large number of major histocompatibility complex (MHC) class I-II positive cells were seen by immunohistochemical methods in SSPE brains, especially in a perivascular distribution. By morphological criteria, HLA -DR positive microglia and reactive astrocytes were also identified. (Hofman et al., 1991). Although cell mediated immunity was found to be abnormal in a small series of patients such as our own where 11/15 patients had some evidence of such an impairment (Handzel et al.,1983), no specific immune defect was found in SSPE (Schneider-Schaulies et al., 2003). The inflammatory perivascular cell infiltrates are predominantly CD4+ T cells, while B cells are seen more frequently in parenchymal inflammatory infiltrates. We have shown in 11 patients with SSPE, that similar to matched controls, they had no detectable plasma interferon (INF) activity. However, their PBMC failed to produce INF following stimulation with polyinosinic:polycytidilic acid (poly I:C and Phytohemagglutinin (PHA) (Gadoth et al., 1989)

\section{Pathophysiology}

One of the prevailing theories suggests that in spite of the lack of evidence for a specific immune defect causing SSPE, impaired immune response plays an important role in its pathophysiology. The observation that early infection with MV virus at the time when the immune system is relatively immature, is associated with increased risk for SSPE (Tuxhorn, 2004), was a pivotal step in understanding the disease. Normally, during the incubation phase of measles, the invading virus induces a cell mediated immune response with activation of T-Helper 1 (Th1) lymphocytes, release of INF- $a$, and interleukin 2 (IL-2), which is capable of eradicating the invading virus particles from the infected cells. Following the characteristic measles papulo-macular skin rash, a humoral antibody mediated long term immunity against future infection is established via the production of Th2 lymphocytes, release of mainly IL- 4 and to a lesser extent INF-a and IL-2. (Griffin et al., 1994). Due to genetic polymorphism, patients with SSPE have an inadequate cellular immune responses to common antigens and produce markedly decreased amounts of IFN (Handzel et al., 1983), and IL - 2,10,12, while producing increased amounts of IL -4 and IL-1b. (Yentür et al., 2005). The induction of this set of humoral immune responses in patients with SSPE rather than producing a cellular immune response which is capable of completely eradicate the MV from the infected cells, is believed to play a major role in the pathogenesis of the disease and contributes to the ability of the mutated measles virus to persist in a dormant form within the brain. (Inoue et al., 2002).

The variable incidence rates of SSPE in different populations and ethnic groups can be partially attributed to genetic polymorphism in addition to a number of epidemiological variables which will be discussed below.

Measles virus uses the cluster of differentiation (CD) protein 46 and fusion protein (protein F), to invade the neuron. The fact that high antibody titers to CD9 were detected in CSF of patients with SSPE who had severe brain atrophy, indicates that this protein plays also a role in neuronal invasion of the virus (Shimizu et al., 2002). After entering the cell the viral 
matrix protein undergoes mutations and cannot be recognized by the immune system. This is followed by virus replication and persistence within the infected cell without being eradicated by the immune system (Makhortova et al., 2007). In addition, a truncated protein F receptor may also play a causative role. Neurokinin-1 is implicated in the spread of the mutated virus to adjacent cells. After a variable period when the virus is dormant, it induces an inflammatory immune mediated reaction directed against the infected cells, which results in widespread CNS damage. Those mentioned immune mechanisms may also play a role in other chronic demyelinating CNS disorders.

\section{Treatment}

SPEE is always fatal. A relative beneficial effect was achieved with either daily oral Isoprinosine or in combination with weekly intrathecal INF - a. Although this combination is considered the most beneficial, approximately $22 \%$ of the treated patients suffered from complications related to the intrathecal reservoir. Isoprinosine (Inosiplex ${ }^{\mathrm{R}}$ ), is a derivative of Inosine and p-acetamidobenzoic acid salt of N,N-dimethylamydo-2- propanol. This drug is considered as an immunomodulator agent capable of impairing viral replication. It is quite safe when given for extended periods of time. The positive immunomodulation effect of Isoprinosine was demonstrated by an experiment during which PBMC of patients with SSPE failed to produce INF after stimulation with poly I:C and PHA. The patients were then given oral Isoprinosine for several days which resulted in significant elevation of serum INF and corrected the failure of INF production by the similarly stimulated PBMC. Moreover, 10 days after discontinuation of the drug, the INF system returned to its inactive state. Several patients were treated for extended periods of time with a $20 \%$ remission rate and or 4 year survival. (Gadoth et al., 1989). Other investigators have shown a beneficial effect of the drug in up to $30-35 \%$ of the patients which is significantly higher than the reported $5 \%$ spontaneous remission rate (Dyken et al., 1982).

Other agents such as Ribavirin, which blocks RNA polymerase without and in combination with INF, Anti CD2O antibodies, THF, Amantadine, Steroids and plasmapehresis showed some beneficial effect in selected non-randomized trials.

Several patients have been treated with intraventricular INF-a alone or in combination with oral Isoprinosine but with no advantage over the intrathecal route (Yalaz et al., 1992).

\section{Epidemiology}

The dramatic changes in the epidemiology of SSPE in relation to the world-wide immunization project against measles are fascinating. The reduction in measles incidence especially in immunized infants was followed by a dramatic fall in the rate of SSPE in the developed countries of the western hemisphere and in other world regions where measles immunization became mandatory. In addition, some changes occurred in the previously described "classical" characteristics of the disease such as the age of onset and a number of clinical features. In a relatively recent world wide review of the rate of measles and SSPE before and after the institution of measles immunization, the dramatic drop in the incidence of SSPE due to immunization was clearly shown (Campbell et al., 2007).

Israel served and still serves as a good site for classical epidemiological studies because of its heterogenic ethnic population, high standard of medical care and a well organized medical and health system which enables the particular researcher to obtain well 
documented data throughout the country. For this reason data from Israel can provide an excellent example of the role of mass measles immunization on the rate of SSPE. The country has a wide-spread network of Mother and Child health clinics which serve the entire county's population. The individual clinics keep careful records of each child's immunization program, and the medical staff is alert to those who fail to show for their clinic visits or to the immunization schedule, established by the Israeli Ministry of health. Due to the nominal cost of those services, it can be assumed that the diagnosis and reports of patients with SSPE are accurate and most probably complete. Population studies of SSPE were carried out in Israel since 1960, while mass measles vaccination was introduced in 1967. Thus, most of the children born after February 1965 were immunized. Considering the standard of medical care in Israel and the size of its population in 1975 (3.5 million), it can be assumed that a rare disease such as SSPE was reported in sufficient numbers during those years when the local and world wide SSPE "epidemic" suddenly emerged. All those factors enabled an accurate analysis of SSPE incidence in regard to a number of variables including the role of mass immunization against measles. Zilber (Zilber et al., 1983), obtained data on SSPE rates from the Israeli National Neurological Disease Register which received notification on all neurological disorders recorded in all hospitalized patients around the country. Death certifications with a code for any neurological disorder were also retrieved. Assuming that the varied and dramatic symptoms of SSPE will eventually lead to hospitalization of the affected child, it is highly likely that the register was notified of almost all patients with SSPE during the period of this study which covered the period of 19681979. The medical records of all detected cases were obtained. As the register was notified also on cases of measles encephalitis, non-specific encephalitis, and degenerative progressive neurological diseases in children, the charts of such cases were also obtained and reviewed for possible SSPE. The records from the central virology laboratory which performed serum and CSF measles antibody titers for the entire country since 1968 until the publication of the mentioned study were searched for tests with increased measles antibody titers and the patients details and medical records were obtained. In a previous study by the same group (Soffer et al., 1975) the medical records of patients with the diagnosis of SSPE from all Israeli hospitals for the period of 1960-1973 were reviewed. In addition, the departments of paediatrics, neurology and the EEG laboratories across the country were asked to provide information on additional patients. The multi-source information thus gathered enabled to exclude multiple reports of the same patient and provided a high level of ascertainment of the data obtained. The main findings of this study confirmed the presence of a steep drop in incidence of SSPE in vaccinated Israeli children noted mainly in 1977, 10 years after the initiation of mass immunization. The rate of SSPE remained low at the completion of this study in 1979. The calculated rate of SSPE (per $10^{6}$ live births) during the period of 1965-1971 was 246 in non vaccinated patients compared to 27 in vaccinated subjects. The rate of 27 included patients who developed measles after immunization. When those patients were excluded the rate dropped to 17. The relation between the rate of measles infection and SSPE in Israel is shown in Figure 4. The rates of SSPE for Israeli Jews and Arabs were compared to rates for Arabs living in Gaza and the west bank where measles immunization was not compulsory but available. The rates dropped steeply for both Israeli Jews and Arabs in 1977 with a significant delay in Gaza and the west bank. However, even in this particular population the decline in the number of new cases was dramatic to the point that no new cases were reported in both populations after 1986 (Figure 5). 


\section{MEASLES CASES AND INCIDENCE OF SSPE ISRAEL 1963-1979}

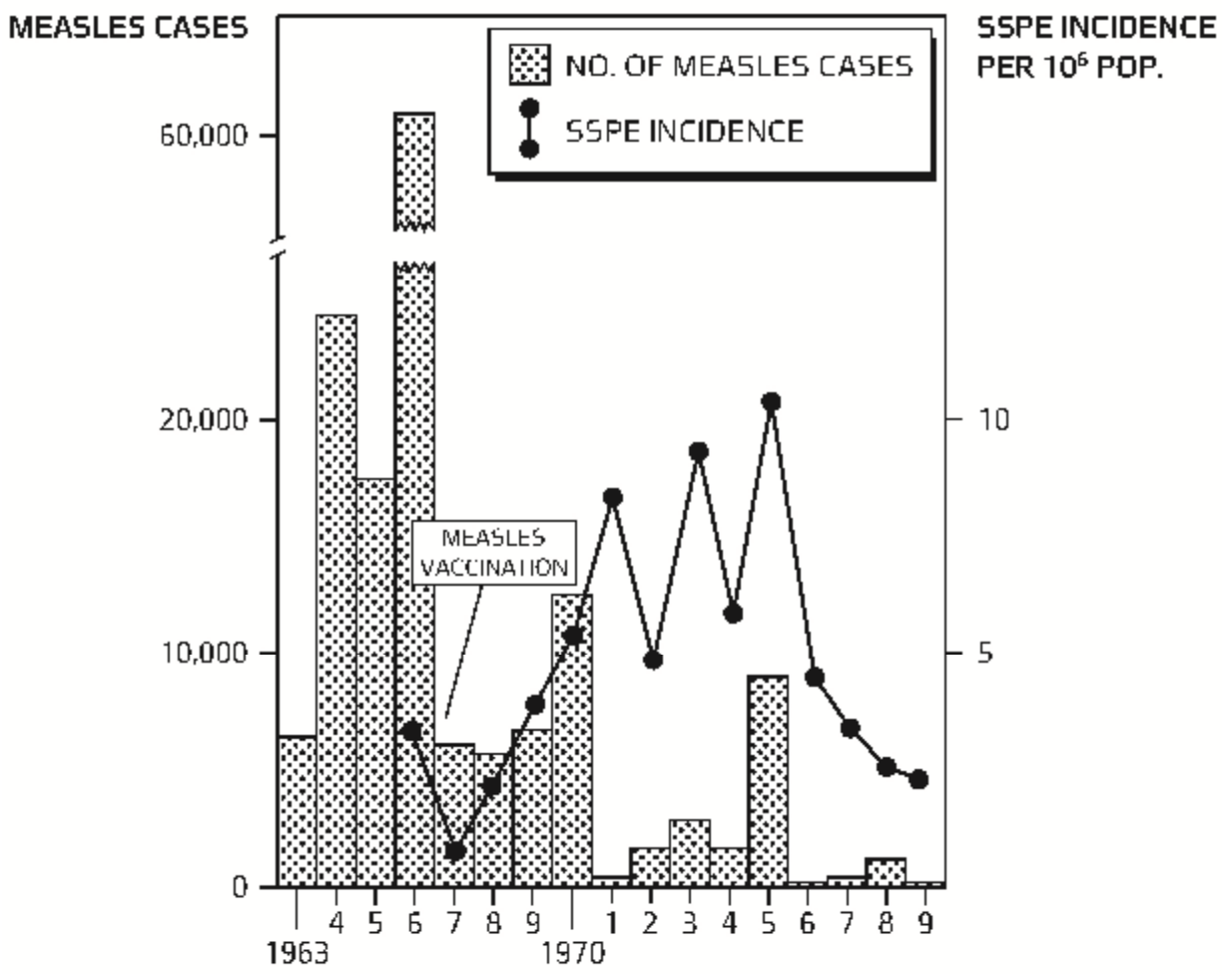

YEARS

Fig. 4. The incidence of SSPE in relation to the rate of measles infection in Israel during the epidemic years of SSPE.

Similar to data from other countries, the age of onset in Israeli patients increased parallel to the decrease in the rate of measles and SSPE, although in Arabs it remained around 10 years of age. (Figure 6).

While new cases are a rarity today in counties with good measles control such as USA where the rate is very low $\left(0.01 / 10^{6}\right)$, it is still quite high in counties with poor measles control (India; 21/106, Japan; 11/106, and Turkey; 0.461/106,(Gutierrez et al., 2010). One of the highest rates of SSPE was found and is still present in Papua- New Guinea (PNG). This rate is only partially related to poor immunization control. During the years 1988-1999, a rate of 13-98/106 was found in individuals younger than 20 years of age. The rate of measles immunization in this particular population was stable at a level between 50-60\% of the population at risk during 1997-2008. A recent study from the referral hospital of the Madang Province in PNG mentioned a rate of 54/106 in individuals younger than 20 years, during 2007-2009. The rate was much higher in 4 sub-districts with an annual incidence of $>100 / 10^{6}$ among the same age group. Those rates are the highest ever reported. The patients in this study contracted measles during their first year of life in 2002 and presented 
with SSPE 6-7 years later. A possible explanation for that very high rate in spite of a $60 \%$ rate of measles immunization in this region is the observation that only $36 \%$ of young Melanesian children respond well to measles vaccine and develop immunity to measles.(Manning et al., 2011).

From the above mentioned epidemiological data it is evident that SSPE is a "vanishing" disease in well developed countries while the disease is still taking the life of children in underdeveloped world regions. The variable incidence of SSPE can be explained not only in relation to the variability in measles morbidity, the degree of immunization coverage, the age of immunization, the different rates of virus mutations, male gender preponderance and ethnic origin, but it is also related to genetic polymorphism which determines the individual immune system reaction to measles vaccine as it happened in PNG.

The different ethnic susceptibility to SSPE was studied in the multiethnic Israeli population. It was found that SSPE was more frequent among Sephardic than Ashkenazi Jews (3.4 vs. $0.5 / 10^{6}$, respectively) (Zilber et al., 1998).

SSPE IN ISRAEL

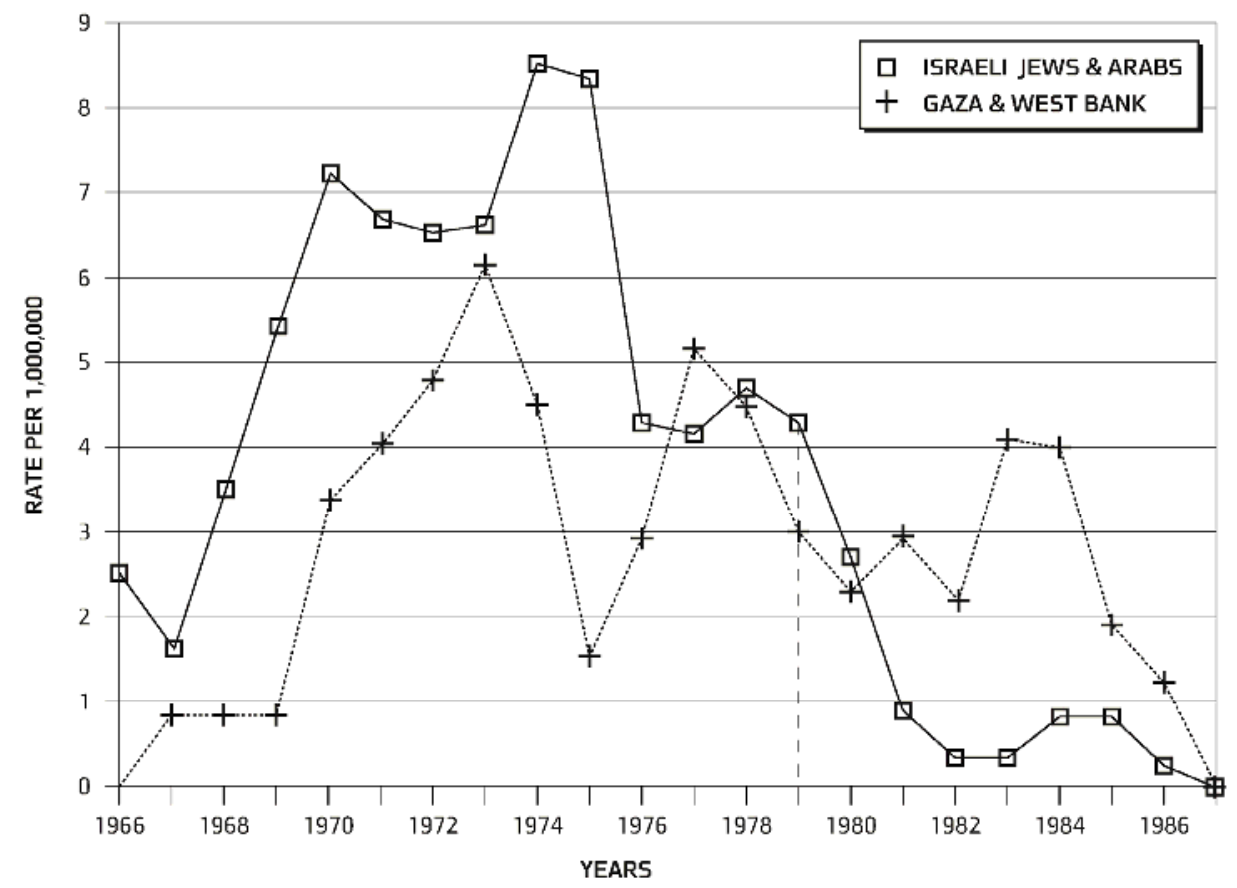

Fig. 5. Differences in incidence of SSPE between Israel and Gaza -West bank. Note the dramatic drop in the incidence in both populations (Vertical broken line). 
SSPE IN ISRAEL BY AGE OF ONSET O

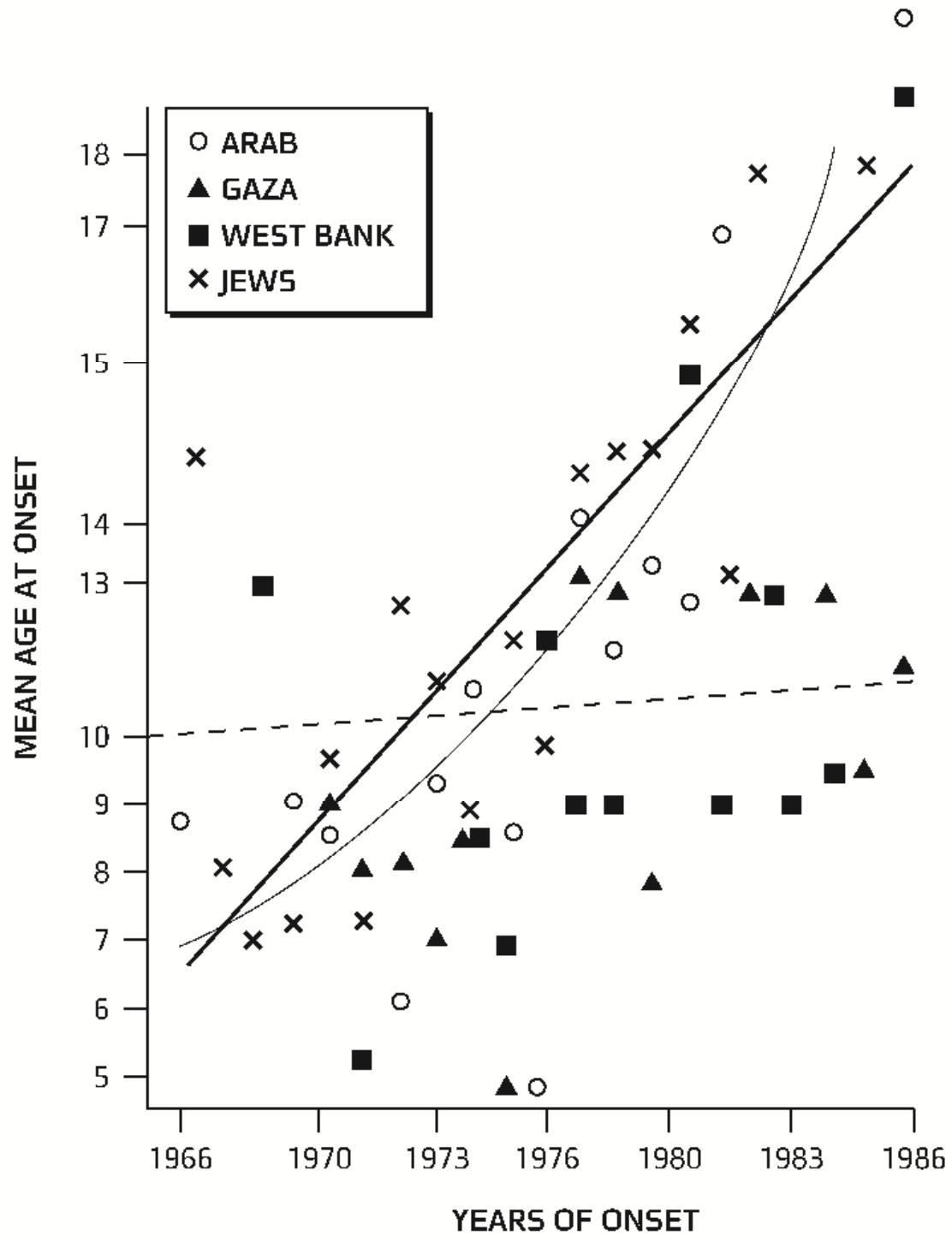

Fig. 6. The increase in age of onset in Jewish Israeli patients with SSPE which followed the steep decline in the incidence of SSPE. 


\section{Conclusion}

SSPE can be added to the past pandemics such as small pox and poliomyelitis which were eradicated due to mass vaccination creating a world wide and an almost complete immunity to those devastating diseases. Although SSPE is not an acute infection "per se " like those mentioned above, this horrible disease was also eradicated due to mass immunization initiated when the "old" traditional methods of keen clinical judgment, basic epidemiology and the progress made by understanding the mechanisms involved in persistent viral infections made it clear that early infection with measles can cause SSPE.

There is still an urgent need to lower the rate of SSPE in areas with poor measles immunization coverage. Although we are at present unable to offer efficient treatment and cure to patients with a variety of degenerative progressive neurological disorders there are some hints to suggest that some of them might be the result of yet unknown "slow virus" infections.

\section{Acknowledgment}

I would like to thank Professor E. Kahana MD, one of the most enthusiastic pioneers of neuro-epidemiological research, who studied the epidemiology of degenerative progressive neurological disorders in Israel, among them, multiple sclerosis, Creutzfeldt- Jacob disease and SSPE. She has willingly provided some of the diagrams shown in this chapter which have not been published before.

\section{References}

Allen, IV. McQuaid, S. McMahon, J. Kirk, J. \& McConnell, R. (1996). The significance of measles virus antigen and genome distribution in the CNS in SSPE for mechanism of viral spread and demyelination, Journal of Neuropathology and Experimental Neurology, Vol.55, No 4, (April 1996), pp. 471-480, ISSN 0022-3069

Aydin, K. Okur, O. Tatli, B. Sarwar, SG, Ozturk, C. \& Dilber, C. (2009), Reduced Gray Matter Volume in the Frontotemporal Cortex of Patients with Early Subacute Sclerosing Panencephalitis., American Journal of Neuroradiology, Vol. 30, No. 2, (February 2009), pp. 271-275, ISSN 0195-6108

Boutellie, M. Fontaine, C. \& Vedrenne, CL. (1965). Sur un cas d'encephalite subaigue a inclusions. Etude Anatomoclinique et ultrastructurale. Revue neurologique, Vol. 113, No. 4, (October 1965), pp. 454-458, ISSN 0035-3787

Cherian, A. Sreedharan, S. Raghavendra, S. Nayak, D. \& Radhakrishnan,A.(2009).Periodic lateralized epileptiform discharges in fulminant form of SSPE. The Canadian Journal of Neurological Sciences, Vol. 36, No. 4, (July 2009), pp. 524-526, ISSN 0317-1671

Connolly, JH. Allen, IV. Hurwitz, LI. \& Millar, JH. (1967). Measles virus antibody and antigen in subacute sclerosing panencephalitis. Lancet, Vol. 1, No. 7489, (March 1967), pp. 542-544, ISSN 0140-6736

Dawson, JR. (1933). Cellular inclusions in cerebral lesions of lethargic encephalitis. American Journal of Pathology , Vol. 9, No 1. (January 1933), pp. 7-15, ISSN 0002-9440

Dawson, JR. (1934). Cellular inclusions in cerebral lesions of epidemic encephalitis. Archives of Neurology and Psychiatry, Vol. 31, No. 4, (April 1934) , pp. 685-700, ISSN 0096-6754 
Demir, E. Ozcelik, A. Arhan, E. Serdaroglu, A. \& Gucuyener, K. (2009). Atypical presentations of subacute sclerosing panencephalitis in two neurologically handicapped cases. Neuropediatrics, Vol. 40, No. 4, (August 2009) , pp. 195-198,ISSN 0174-304X

Dyken, PR. Swift, A. \& DuRant, RH. (1982). Long-term follow-up of patients with subacute sclerosing panencephalitis treated with inosiplex. Annals of Neurology Vol. 11, No. 4, (April 1982), pp. 359-364, ISSN 0364-5134

Fabian, VA. Yee Lee, H. Keith-Rokosh, JL. de Souza, JL. \& Stewart-Wynne, E. (2010). A 22year-old Australian woman with atypical subacute sclerosing panencephalitis diagnosed at postmortem. Journal of Clinical Neuroscience, Vol. 17, No. 9, (September 2010), pp. 1192-1194, ISSN 0967-5868

Gadoth, N. Kott, E. Levin, S. \& Hahn, T. (1989). The interferon system in subacute sclerosing panencephalitis and its response to Isoprinosine. Brain and Development Vol. 11, No. 5, (May 1989), pp. 308-312, ISSN 0387-7604

Greenfield, JG. (1950). Encephalitis and encephalomyelitis in England and Wales during the last decade. Brain. Vol. 73, No. 2,(June 1950), pp. 141-166, ISSN 0006-8950

Griffin, DE. Ward, BJ. \& Esolen, LM. (1994). Pathogenesis of measles virus infection: a hypothesis for altered immune responses. Journal of Infectious Diseases, Vol. 170, Suppl. 1, (November 1994), pp. S24-S31, ISSN 1344-6304

Gutierrez, J. Issacson, RS. \& Koppel, BS. (2010). Subacute sclerosing panencephalitis: an update. Developmental Medicine and Child Neurology, Vol. 52, No.10, (October 2010), pp. 901-907, ISSN 1469- 8749

Handzel, Z. Gadoth, N. Idar, D. Schlesinger, M. Kahana, E. Dagan, R. Levin, S. \& Trainin N. (1983). Cell mediated immunity and effect of "thymic humoral factor " in 15 patients with SSPE. Brain and Development, Vol. 5, No. 1,(January 1983) , pp. 29-35, ISSN 0387-7604

Hayashi, M. Arai, N. Satoh, J. Suzuki, H. Katayama, K. Tamagawa, K. \& Morimatsu, Y. (2002). Neurodegenerative mechanisms in subacute sclerosing panencephalitis. Journal of Child Neurology, Vol. 17, No. 10, (October 2002), pp. 725-730, ISSN 08830738

Hofman, FM. Hinton, DR. Baemayr, J. Weil, M. \& Merrill, JE. (1991). Lymphokines and immunoregulatory molecules in subacute sclerosing panencephalitis. Clinical Immunology and Immunopathology. Vol. 58, No. 3, (March 1991), pp. 331-342, ISSN 0090-1229

Inoue, T. Kira, R. Nakao, F. Thara, K. Bassuny, WM. Kusuhara, K. Nihei, K. Takeshita, K. \& Hara, T. (2002). Contribution of the interleukin 4 gene to susceptibility to subacute sclerosing panencephalitis. Archives of Neurology, Vol. 59, No. 5, (May 2002), pp. 822-827, ISSN 0003-9942

Kissani, N. Ouazzani, R. Belaidi, H. Ouahabi, H. \& Chkili, T. (2001).Crises épileptiques et épilepsie dans le cadre d'une panencéphalite sclérosante subaiguë (à propos de 30 cas). Neurophysiologie Clinique, Vol. 31, No. 6, (December 2001), pp. 398-405, ISSN 0987-7053

Makhortova, NR. Askovich, P. Patterson, CE. Gechman, LA. Gerard, NP. \& Rall, GF. (2007). Neurokinin-1 enables measles virus trans-synaptic spread in neurons. Virology, Vol. 362, No. 1, (May 2007), pp. 35-44, ISSN 0042-6822 
Manning, L. Laman, M. Edoni, H. Mueller, I. Karunajeewa, HA. Smith, D. Hwaiwhanje, I. Siba, PM. \& Davis, TME. (2011). Subacute Sclerosing Panencephalitis in Papua New Guinean Children: The Cost of Continuing Inadequate Measles Vaccine Coverage. Public Library of Science (PLoS) Neglected Tropical Diseases, Vol. 5, No. 1, (January 2001), pp. e932 (1-8). ISSN 1935-2735

McQuaid, S. Allen, IV. McMahon, J. \& Kirk, J. (1994). Association of measles virus with neurofibrillary tangles in subacute sclerosing panencephalitis: a combined in situ hybridization and immunocytochemical investigation. Neuropathology and Applied Neurobiology, Vol. 20, No. 2, (April 1994), pp. 103-110, ISSN 0305-1846

Pette, H, \& Döring, G.(1939). Über einheimische panencephalomyelitis vom charaker der encephalitis japonica. Deutsche Zeitschrift fur Nervenheilkunde, Vol. 149, No. 1-2, (June 1939), pp. 7-44, ISSN 0340-5354

PeBenito, R. Naqvi, SH. Arca, MM. \& Schubert, R. (1997). Fulminating subacute sclerosing panencephalitis: case report and literature review. Clinical Pediatrics (Phila), Vol. 36, No. 3, (March 1997), pp.-149-154, ISSN 0009-9228

Poser, CM. \& Radermecker, J. (1957). Subacute Scelorsing leucoencephalitis. Journal of Pediatrics, Vol. 50, No. 4, (April 1957), pp. 408-425, ISSN 0022-3476

Prashanth, LK. Taly, AB. Ravi, V. Sinha, S. \& Arunodaya, GR. (2006). Adult onset subacute sclerosing panencephalitis: clinical profile of 39 patients from a tertiary care centre. Journal of Neurology Neurosurgery and Psychiatry, Vol. 77, No. 5, (May 2006), pp. 630633, ISSN 0022-3050

Praveen- kumar, S. Sinha, S. Taly, AB. Jayasree, S. Ravi, V. Vijayan, J. \& Ravishankar, S. (2007). Electroencephalographic and imaging profile in a subacute sclerosing panencephalitis (SSPE) cohort: A correlative study. Clinical Neurophysiology, Vol. 118, No. 9, (September 2007), pp. 1947-1954, ISSN 1388-2457

Santoshkumar, B. \& Radhakrishnan, K. (1996). Periodic electroencephalographic pattern in subacute sclerosing panencephalitis modified by preexisting damaged cerebral hemisphere. Electroencephalogry and Clinical Neurophysiology, Vol. 99, No 5, (November 1996), pp. 440-443, ISSN 0013-4694

Schneider-Schaulies, J. Meulen, V. \& Schneider-Schaulies, S. (2003). Measles infection of the central nervous system. Journal of Neurovirology, Vol. 9, No. 2, (April 2003), pp. 247252, ISSN 1355-0284

Shimizu, T. Matsuishi, T. Iwamoto, R. Handa, K. Yoshioka, H. Kato, H. Ueda, S. Hara, H. Tabira, T. \& Mekada, E. (2002). Elevated levels of anti-CD9 antibodies in the cerebrospinal fluid of patients with subacute sclerosing panencephalitis. Journal of Infectious Diseases, Vol. 185, No. 9, (May 2002), pp- 1346-1350, ISSN 1344-6304

Singer, C. Lang, AE. \& Suchowersky, O. (1997). Adult-onset subacute sclerosing panencephalitis: case reports and review of the literature. Movement Disorders. Vol. 12, No. 3, (May 1997), pp. 342-353, ISSN 0885-3185

Soffer, D. Rannon, L. Alter, M. Kahana, E. \& Feldman, S.(1975). Subacute scerosing panencephalitis: incidence among ethnic groups in Israel. Israel Journal of Medical Sciences, Vol. 11, No. 1, (January 1975), pp. 1-4, ISSN 0021-2180

Tuxhorn, IE. (2004). Familial subacute sclerosing panencephalitis in two siblings. Pediatric Neurology Vol. 31, No. 4, (October 2004), pp. 291-294, ISSN 0887-8994

Van Bogaert, L. (1945). Une leocoencephalite sclerosante subaigue. Jouranl of Neurolorgy, Neurosurgery \& Psychiatry, Vol. 8, No. 3-4, (July 1945), pp. 101-120, ISSN 0022-3050 
Yalaz, K. Anlar, B. Oktem, F. Aysun, S. Ustacelebi, S. Gurcay, O. Gucuyener, K. \& Renda, Y. (1992). Intraventricular interferon and oral inosiplex in the treatment of subacute sclerosing panencephalitis. Neurology, Vol. 42, No. 3, (March 1992), pp-488-491, 0028-3878

Yentür, SP. Gürses, C. Demirbilek, V. Yilmaz, G. Onal, AE. Yapici, Z. Yalçinkaya, C. Cokar, O. Gökyiğit, A. \& Saruhan-Direskeneli, G. (2005). Alterations in cell-mediated immune response in subacute sclerosing panencephalitis. Journal of Neuroimmunology, Vol. 170, No. 1-2, (December 2005), pp. 179-185,ISSN 0165-5728

Zilber, N. Rannon, L. Alter, M. \& Kahana, E. (1983). Measles, measles Vaccination and risk of subacute sclerosing panencephalitis (SSPE). Neurology Vol. 33, No. 12, (December 1983), pp. 1558-1564,ISSN 0028-3878

Zilber, N. \& Kahana, E. (1998). Environmental risk factors of subacute scleroisng panenecephalitis (SSPE). Acta Neurologica Scandinavica, Vol. 98, No. 1, (July 1998), pp. 49-54, ISSN 0001-6314 


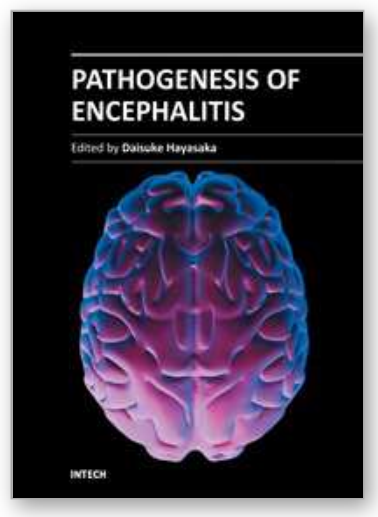

\author{
Pathogenesis of Encephalitis \\ Edited by Dr. Daisuke Hayasaka
}

ISBN 978-953-307-741-3

Hard cover, 344 pages

Publisher InTech

Published online 09, December, 2011

Published in print edition December, 2011

Many infectious agents, such as viruses, bacteria, and parasites, can cause inflammation of the central nervous system (CNS). Encephalitis is an inflammation of the brain parenchyma, which may result in a more advanced and serious disease meningoencephalitis. To establish accurate diagnosis and develop effective vaccines and drugs to overcome this disease, it is important to understand and elucidate the mechanism of its pathogenesis. This book, which is divided into four sections, provides comprehensive commentaries on encephalitis. The first section (6 chapters) covers diagnosis and clinical symptoms of encephalitis with some neurological disorders. The second section ( 5 chapters) reviews some virus infections with the outlines of inflammatory and chemokine responses. The third section ( 7 chapters) deals with the non-viral causative agents of encephalitis. The last section ( 4 chapters) discusses the experimental model of encephalitis. The different chapters of this book provide valuable and important information not only to the researchers, but also to the physician and health care workers.

\title{
How to reference
}

In order to correctly reference this scholarly work, feel free to copy and paste the following:

Natan Gadoth (2011). Subacute Sclerosing Pan-Encephalitis (SSPE) - Past and Present, Pathogenesis of Encephalitis, Dr. Daisuke Hayasaka (Ed.), ISBN: 978-953-307-741-3, InTech, Available from:

$\mathrm{http}: / / \mathrm{www}$.intechopen.com/books/pathogenesis-of-encephalitis/subacute-sclerosing-pan-encephalitis-sspepast-and-present

\section{INTECH}

open science | open minds

\section{InTech Europe}

University Campus STeP Ri

Slavka Krautzeka 83/A

51000 Rijeka, Croatia

Phone: +385 (51) 770447

Fax: +385 (51) 686166

www.intechopen.com

\section{InTech China}

Unit 405, Office Block, Hotel Equatorial Shanghai

No.65, Yan An Road (West), Shanghai, 200040, China

中国上海市延安西路65号上海国际贵都大饭店办公楼 405 单元

Phone: +86-21-62489820

Fax: $+86-21-62489821$ 
(C) 2011 The Author(s). Licensee IntechOpen. This is an open access article distributed under the terms of the Creative Commons Attribution 3.0 License, which permits unrestricted use, distribution, and reproduction in any medium, provided the original work is properly cited. 